\title{
Analysis of Risk Factors for Non-Union After Surgery for Limb Fractures: A Case-Control Study of 669 Subjects
}

\section{Qiang Xu}

First Affiliated Hospital of Nanchang University

\section{Bin Zhang}

First Affiliated Hospital of Nanchang University

Min Dai

First Affiliated Hospital of Nanchang University

Xuqiang Liu ( $\nabla$ shliuxuqiang@163.com )

First Affiliated Hospital of Nanchang University https://orcid.org/0000-0003-3361-8969

\section{Research article}

Keywords: Limb fractures, Bone non-union, Fracture healing, Risk factors, Multivariate logistic regression

Posted Date: September 15th, 2020

DOI: https://doi.org/10.21203/rs.3.rs-74785/v1

License: @ (i) This work is licensed under a Creative Commons Attribution 4.0 International License. Read Full License 


\section{Abstract}

Objective: Although a large number of clinical and animal experimental studies have explored factors affecting fracture healing, there are only a few examples of systematic research on these factors for limb fractures. The purpose of this study was to analyse the risk factors for limb fracture non-union in order to improve non-union prevention and early detection.

Methods: A total of 223 patients with non-union after surgery for limb fractures performed at our institution from January 2005 to June 2017 were included as the case group, while a computer-generated random list was created to select 446 patients with successful bone healing who were treated during the same period as the control group, thus achieving a ratio of 1:2. The medical records of these patients were reviewed retrospectively. Age, sex, body mass index, obesity, smoking, alcohol, diabetes, hypertension, osteoporosis, fracture type, multiple fractures, non-steroidal anti-inflammatory drugs (NSAIDs) use, delayed weight bearing, internal fixation failure, and infection data were analysed and compared between the two groups. A multivariate logistic regression model was constructed to determine relevant factors associated with non-union.

Results: The multivariate logistic regression analysis revealed that osteoporosis, open fractures, NSAIDs use, delayed weight bearing, failed internal fixation, and infection were independent risk factors for nonunion after surgery for limb fractures.

Conclusions: Osteoporosis, open fracture type, NSAIDs use, delayed weight bearing, failed internal fixation, and infection were found to be the main causes of bone non-union; clinicians should, therefore, take targeted measures to intervene in high-risk groups early.

\section{Introduction}

Recently, the number of patients with successful callus formation after fracture surgical management has decreased, with $5-10 \%$ of non-union cases leading to worrying outcomes [1, 2]. The loss of productivity caused by a long healing process affects patients, healthcare systems, and the economy [3]. It is estimated that 100,000 fracture cases show non-union in the United States each year, with the cost of non-union complications being close to $\$ 12,000$ per patient $[4,5]$. In addition, in the United Kingdom, the cost of treating non-union is estimated at $£ 7000$ to $£ 79,000$, but these figures relate only to the cost of hospitalisation $[6,7]$, which indicates that a large amount of medical resources are consumed each year in non-union cases.

Risk factors can determine which patients may benefit from more active interventions among those who tend to develop non-union, and a clear idea of the risk of non-union may help to choose between competing treatment options [8]. Identifying these factors will enable surgeons to identify high-risk cases before surgery in order to implement measures to promote healing, such as more comprehensive metabolic examinations, medical interventions, early bone grafting, and the use of osteoinductive agents and bone stimulants [9]. Furthermore, these findings will help surgeons consult on the anticipated 
outcomes of such patients. Bone non-union is a multifactorial disease, and it is considered that the coexistence of different risk factors is crucial to its occurrence. A series of factors have been considered to be the causes of non-union, which can be divided into two main categories: (1) patient-related factors [8], including age and sex, body mass index (BMI), obesity, smoking, alcohol, and medical history of diabetes, hypertension, and osteoporosis; and (2) injury characteristics and treatment-related factors [10], including fracture type, use of nonsteroidal anti-inflammatory drugs (NSAIDs), delayed weight bearing, mechanical instability resulting in internal fixation failure, and infection.

Until now, although a large number of studies have been conducted to analyse the multiple risk factors involved in the development of fracture non-union, they are limited by small sample sizes and incomplete potential risk factors [11-14]. Moreover, clinical trials have shown that changes in the rate of non-union are related to different surgical treatments $[15,16]$. However, the above factors cannot fully explain the occurrence of non-union. Most of these studies reported fractures at specific sites, such as the humerus, femur, or tibia, or were limited to one type of non-union, such as that caused only by biological or treatment-related factors, without a systematic and global analysis that is required for limb fractures.

The purpose of this study was, therefore, to investigate the association between the occurrence of nonunion after surgery for limb fractures and patient-, injury-, and treatment-related factors. A thorough understanding of these factors and their relative impact may provide better insight into the causes of non-union and the required treatment. Modifiable factors, such as use of NSAIDs and delayed weight bearing, should be strictly evaluated to optimise the patient prognosis.

\section{Methods}

\section{Study design}

We retrospectively analysed 223 patients with bone non-union after surgery for limb fractures in our institution from January 2005 to June 2017 (case group), and created a computer-generated random list to select 446 patients with successful bone healing after surgery for limb fractures (control group), thus achieving a case-control ratio of 1:2. Both groups of patients were treated during the same period. The inclusion criteria were as follows: a) meeting the diagnostic criteria for bone non-union for the case group: fracture not completely healed within 9 months after injury and showing no progression toward healing on radiographs for 3 consecutive months; b) a clear history of trauma; c) fracture of the humerus, ulna, radius, femur, tibia, or fibula. The exclusion criteria were as follows: a) comorbid severe loss of other major organs, severe malnutrition, or malignant disease; $b$ ) severe bone defect requiring bone grafting; $c$ ) incomplete clinical data.

\section{Data collection}

All cases of limb fractures were treated surgically by experienced doctors in our institution. Postsurgically, the use of NSAIDs such as flurbiprofen and celecoxib was decided according to the patients' pain.

Delayed weight bearing was defined as starting weight bearing more than 12 weeks after surgery, and 
failure of internal fixation was defined as screw loosening, screw fracture, plate fracture, intramedullary nail fracture, and internal fixation rejection. Additionally, all patients were followed up at 1, 3, 6, and 12 months after surgery, which included clinical and X-ray examinations to observe wound healing, internal fixation, fracture healing, and joint function. The collected patient-related data included age, sex, BMI, obesity, smoking, alcohol, diabetes, hypertension, osteoporosis, fracture type, multiple fractures, use of NSAIDs, delayed weight bearing, failed internal fixation, and infection to further analyse risk factors for non-union.

\section{Statistical analyses}

Continuous variable data are presented as mean \pm standard deviation, and discrete variable data are presented as frequencies. The Shapiro-Wilk test was used to test the normality of continuous variables, and the independent-samples t-test was used to compare differences in age and BMI between the case and the control groups. The chi-square test and Spearman correlation coefficient were used to test and analyse differences in other data. To determine the most significant risk factors for bone non-union, multivariate logistic regression analysis and forward stepwise regression were used to analyse the risk factors. All the above analyses were carried out using SPSS 26.0 statistical software (IBM Corp., Armonk, NY, USA). P-values $<0.05$ were considered statistically significant.

\section{Results}

As shown in Table 1, there were 223 patients in the case group with an average age of $39.8 \pm 14.7$ years (167 males and 56 females) and 446 patients in the control group with an average age of $38.1 \pm$ 15.6 years (309 males and 137 females). There was no significant difference in average age and sex ratio between the two groups. The average $\mathrm{BMI}$ of patients in the case group was higher than that of patients in the control group $\left(24.0 \pm 4.7 \mathrm{~kg} / \mathrm{m}^{2} \mathrm{vs}\right.$. $\left.22.6 \pm 4.9 \mathrm{~kg} / \mathrm{m}^{2}\right)$, but this difference was not significant $(P=0.085)$. There were also no significant differences in smoking, alcohol, diabetes, and hypertension between the two groups (Table 1). Conversely, the proportion of patients with a history of osteoporosis was significantly higher in the case group than in the control group [35.4\% (79/223) vs. $12.8 \%$ (57/446); $\mathrm{P}<0.001]$. 
Table 1

Characteristics of the patient-related factors

\begin{tabular}{|c|c|c|c|}
\hline Patient characteristics & Case group $(n=223)$ & Control group $(n=446)$ & $P$ value \\
\hline Age, mean years $( \pm S D)$ & $39.8 \pm 14.7$ & $39.0 \pm 15.2$ & 0.548 \\
\hline $\mathrm{BMl}, \mathrm{kg} / \mathrm{m} 2$ & $24.0 \pm 4.7$ & $22.8 \pm 4.5$ & 0.119 \\
\hline \multicolumn{4}{|l|}{ Obesity (BMI > 30) } \\
\hline Yes & $31(13.9 \%)$ & $51(11.4 \%)$ & \\
\hline No & 192(86.1\%) & $395(88.6 \%)$ & \\
\hline Sex & & & 0.202 \\
\hline Male & $167(74.9 \%)$ & $313(70.2 \%)$ & \\
\hline Female & $56(25.1 \%)$ & $133(29.8 \%)$ & \\
\hline Smoking $(\mathrm{n}, \%)$ & & & 0.359 \\
\hline Yes & $31(13.9 \%)$ & $51(11.4 \%)$ & \\
\hline No & 192(86.1\%) & $395(88.6 \%)$ & \\
\hline Alcohol (n, \%) & & & 0.326 \\
\hline Yes & $18(8.1 \%)$ & $27(6.1 \%)$ & \\
\hline No & $205(91.9 \%)$ & $419(93.9 \%)$ & \\
\hline \multicolumn{4}{|l|}{ Medical history $(n, \%)$} \\
\hline Diabetes & & & 0.659 \\
\hline Yes & $7(3.1 \%)$ & $17(3.8 \%)$ & \\
\hline No & $216(96.9 \%)$ & $429(96.2 \%)$ & \\
\hline Hypertension & & & 0.735 \\
\hline Yes & $13(5.8 \%)$ & $29(6.5 \%)$ & \\
\hline No & $210(94.2 \%)$ & $417(93.5 \%)$ & \\
\hline Osteoporosis & & & $<0.001$ \\
\hline Yes & $79(35.4 \%)$ & $57(12.8 \%)$ & \\
\hline No & $144(64.6 \%)$ & $389(87.2 \%)$ & \\
\hline
\end{tabular}

The two groups showed significant differences in the proportion of open fracture, NSAIDs use, delayed weight bearing, failed internal fixation, and infection $(P<0.001)$; only the multiple fracture rate was not significantly different $(P=0.824)$ between the groups (Table 2$)$. Additionally, variables in Table 3 which 
showed significant differences between groups were assessed using multivariate logistic regression, which identified osteoporosis ( $\mathrm{OR}=3.16,95 \% \mathrm{Cl}$ : 2.05 to 4.89 ), open fracture (OR $=2.71,95 \% \mathrm{Cl}: 1.72$ to 4.27), NSAIDs use ( $\mathrm{OR}=2.04,95 \% \mathrm{Cl}: 1.24$ to 3.37$)$, delayed weight bearing ( $\mathrm{OR}=1.72,95 \% \mathrm{Cl}: 1.08$ to 2.74), failed internal fixation ( $\mathrm{OR}=5.93,95 \% \mathrm{Cl}: 2.85$ to 12.36$)$, and infection (OR $=6.77,95 \% \mathrm{Cl}: 2.92$ to 15.69) as independent risk factors for non-union after surgery for limb fractures.

Table 2

Injury characteristics and treatment-related factors

\begin{tabular}{|llll|}
\hline Variable & Case group $(\mathbf{n}=223)$ & Control group $(\mathbf{n}=446)$ & $P$ value \\
\hline Fracture type & & & $<0.001$ \\
\hline Open & $76(34.1 \%)$ & $54(12.1 \%)$ & \\
\hline Closed & $147(65.9 \%)$ & $392(87.9 \%)$ & \\
\hline Multiple fracture & & & 0.824 \\
\hline Yes & $15(6.7 \%)$ & $28(6.3 \%)$ & $<0.001$ \\
\hline No & $208(93.3 \%)$ & $418(93.7 \%)$ & \\
\hline NSAlD & & & $<0.001$ \\
\hline Yes & $66(29.6 \%)$ & $44(9.9 \%)$ & \\
\hline No & $157(70.4 \%)$ & $402(90.1 \%)$ & $<0.001$ \\
\hline Delayed weight bearing & & & \\
\hline Yes & $69(30.9 \%)$ & $66(14.8 \%)$ & \\
\hline No & $154(69.1 \%)$ & $380(85.2 \%)$ & \\
\hline Failed Internal fixation & & & \\
\hline Yes & $44(19.7 \%)$ & $4(1.8 \%)$ & \\
\hline No & $179(80.3 \%)$ & $434(97.3 \%)$ & \\
\hline Infection & & & \\
\hline Yes & $36(16.1 \%)$ & & \\
\hline No & $187(83.9 \%)$ & & \\
\hline
\end{tabular}


Table 3

Multivariable logistic regression model for predictors of non-union

\begin{tabular}{|lll|}
\hline Variable & Odds ratio estimates $(95 \% \mathrm{Cl})$ & $P$ value \\
\hline Osteoporosis & $3.16(2.05-4.89)$ & $<0.001$ \\
\hline Open fracture & $2.71(1.72-4.27)$ & $<0.001$ \\
\hline NSAID & $2.04(1.24-3.37)$ & 0.005 \\
\hline Delayed weight bearing & $1.72(1.08-2.74)$ & 0.023 \\
\hline Failed Internal fixation & $5.93(2.85-12.36)$ & $<0.001$ \\
\hline Infection & $6.77(2.92-15.69)$ & $<0.001$ \\
\hline
\end{tabular}

\section{Discussion}

In this study, we found six predictors of non-union after surgery for limb fractures: osteoporosis, open fracture, NSAIDs use, delayed weight bearing, failed internal fixation, and infection. Other patient- and injury-related factors, such as age, sex, BMI, obesity, smoking, alcohol, hypertension, diabetes, closed fracture, and multiple fractures, were not significant risk factors.

Without controlling for potential confounding factors, it is not clear whether age and sex itself are risk factors for bone non-union. Although the number of patients included in this study is relatively large, it is not sufficient to control the confounding effect of age and sex. Some studies have reported that age and sex are positively correlated with the risk of non-union $[17,18]$, while other reports show that there is no significant correlation $[19,20]$. It is worth noting that the average age of the population in this study is only approximately 40 years old, and the results may not apply to older patients. This may also explain why age-related factors such as obesity, smoking, alcohol, hypertension, and diabetes have not been identified as statistically significant risk factors in this study, despite being suggested as possible causes of bone non-union in previous studies [21-25]. In addition, one study positively found a significant correlation between osteoporosis and the risk of non-union [26], which is in line with the present study's findings. However, another case-control study evaluated 1498 patients and failed to find such an association [27].

In our study, no significant correlation was found between the presence of multiple fractures and nonunion. On the contrary, a previous study showed that non-union seems to be associated with multiple fractures [28]. This discrepancy may be related to the small proportion of non-union $(n=15,6.7 \%)$ in patients with multiple fractures in our study; further studies with larger samples are needed to provide a more definitive understanding of the role of multiple fractures. However, a significant proportion of nonunion cases occurred in patients with open fractures $(n=76,34.1 \%)$, and the multiple regression analysis showed that patients with open fractures have a greater risk of non-union, which was consistent with the results of a previous study [29]. Compared with closed fractures, open fractures are associated with 
relatively greater trauma, more serious destruction of soft tissue blood supply, higher probability of infection, and decreased blood supply, thus affecting bone healing [30]. This also explains that patients with open fractures have a relatively high rate of healing disturbances.

Basic studies have shown that NSAIDs use affects bone healing, mainly due to their inhibiting effect on cyclooxygenase-2, which delays fracture healing [31]. A recent retrospective clinical study of 1900 patients with long bone fractures showed that the postoperative use of NSAIDs doubled the risk of healing complications [32]. Moreover, Giannoudis et al. have demonstrated that there is a highly significant relationship between NSAIDs use and bone non-union $(P<0.001)$ [33]. Our findings suggest that the NSAIDs use after surgery for limb fractures is associated with a 2.04-fold higher odds ratio of non-union, which is in line with the results of previous studies.

It is crucial to start weight bearing after a fracture since it helps maintain bone and muscle mass and helps restore the performance of activities of daily living. Additionally, weight bearing promotes bone healing through a process called mechanical transduction [34]. Recently, a study demonstrated the safety of early weight bearing after fracture surgery [35]. We identified a significant association $(P<0.001)$ between delayed weight bearing after surgery and the development of non-union, which is consistent with the results of the study by Westgeest et al. [36]. Furthermore, delayed weight bearing was identified as an independent risk factor for the development of non-union in the multivariate analysis. This finding may be explained by a relationship between weight bearing and healing outcomes in the reverse direction. That is, bone non-union may cause more pain, resulting in delayed weight bearing, rather than delayed weight bearing causing non-union [37]. Additionally, internal fixation failure is often considered as a reason to postpone the initial weight bearing. In this study, internal fixation failure $(n=44,19.7 \%)$ accounted for a large proportion of bone non-union cases, which indicates that there is some association between failed internal fixation and delayed weight bearing. Indeed, our results showed that failed internal fixation $(\mathrm{OR}=5.93,95 \% \mathrm{Cl}$ : 2.85 to 12.36$)$ significantly increases the risk of non-union.

Different opinions have been put forward on whether there is a connection between infection and nonunion. Most scholars believe that infection does not increase the risk of non-union [38-40]. However, a prospective cohort study evaluated 736 patients and showed that infection was significantly associated with non-union [36]. The results of our analysis show that infection is an independent risk factor for nonunion, with a 6.77-fold higher risk of non-union in patients with infection. There was also a significant correlation between infection and non-union. This may be due to the increased fracture end necrosis and vascular embolism, giving rise to poor local bone blood supply, so that the formation of bone is disturbed and healing is impaired, ultimately resulting in bone non-union [9].

Despite these findings, this study has some limitations. First, although we designed a 1:2 matched casecontrol study to try to minimise the impact of the small sample size, our sample may not fully represent all postoperative patients with limb fractures and may also not be large enough to make our regression analysis conclusive. Second, multiple surgeons were involved in this retrospective study, each with a slightly different non-union definition and treatment. Finally, most patients in this study were middle-aged; 
thus, it is difficult to apply these findings to older patients. Therefore, further research in a wider age range is needed.

\section{Conclusions}

In summary, this study demonstrated that osteoporosis, open fractures, delayed weight bearing, NSAIDs use, failure of internal fixation, and infection are independent risk factors for non-union. Clinically, surgeons should understand these risk profiles in order to effectively guide patients and successfully set appropriate expectations.

\section{Abbreviations}

BMI: body mass index; NSAIDs: non-steroidal anti-inflammatory drugs

\section{Declarations}

\section{Acknowledgements}

Not applicable.

\section{Authors' contributions}

XQ collected the data. XQ, ZB and LXQ wrote the manuscript and did the statistical analysis. LXQ, DM and $X Q$ supervised the study and revised the manuscript. All authors read and approved the final manuscript.

\section{Funding}

This study was supported by the National Natural Science Foundation for Youths (No. 81601912) and National Natural Science Foundation (No. 81660365, 81860404, 81860405)

\section{Availability of data and materials}

The data is available upon request from the corresponding author.

\section{Ethics approval and consent to participate}

Ethical approval for the study was obtained from the institutional review board of The First Affiliated Hospital of Nanchang University. Informed and written consent was obtained from all patients.

\section{Consent for publication}

Not applicable. 
The authors declare that they have no competing interests.

\section{References}

1. Tzioupis C, Giannoudis PV. Prevalence of long-bone non-unions. Injury. 2007;38 Suppl 2:S3-9.

2. Calori GM, Mazza E, Colombo M, Ripamonti C, Tagliabue L. Treatment of long bone non-unions with polytherapy: indications and clinical results. Injury. 2011;42(6):587-90.

3. Reahl GB, Gerstenfeld L, Kain M. Epidemiology, Clinical Assessments, and Current Treatments of Nonunions. Curr Osteoporos Rep. 2020;18(3):157-68.

4. Brinker MR, Trivedi A, O'Connor DP. Debilitating Effects of Femoral Nonunion on Health-Related Quality of Life. J Orthop Trauma. 2017;31(2):e37-e42.

5. Hak DJ, Fitzpatrick D, Bishop JA, Marsh JL, Tilp S, Schnettler R, et al. Delayed union and nonunions: epidemiology, clinical issues, and financial aspects. Injury. 2014;45 Suppl 2:S3-7.

6. Mills LA, Simpson AH. The relative incidence of fracture non-union in the Scottish population (5.17 million): a 5-year epidemiological study. BMJ Open. 2013;3(2).

7. Kanakaris NK, Giannoudis PV. The health economics of the treatment of long-bone non-unions. Injury. 2007;38 Suppl 2:S77-84.

8. Zura R, Mehta S, Della Rocca GJ, Steen RG. Biological Risk Factors for Nonunion of Bone Fracture. JBJS Rev. 2016;4(1).

9. Rodriguez EK, Boulton C, Weaver MJ, Herder LM, Morgan JH, Chacko AT, et al. Predictive factors of distal femoral fracture nonunion after lateral locked plating: a retrospective multicenter case-control study of 283 fractures. Injury. 2014;45(3):554-9.

10. Copuroglu C, Calori GM, Giannoudis PV. Fracture non-union: who is at risk? Injury. 2013;44(11):137982.

11. Fong K, Truong V, Foote CJ, Petrisor B, Williams D, Ristevski B, et al. Predictors of nonunion and reoperation in patients with fractures of the tibia: an observational study. BMC Musculoskelet Disord. 2013;14:103.

12. Drosos GI, Bishay M, Karnezis IA, Alegakis AK. Factors affecting fracture healing after intramedullary nailing of the tibial diaphysis for closed and grade I open fractures. J Bone Joint Surg Br. 2006;88(2):227-31.

13. Dodwell ER, Latorre JG, Parisini E, Zwettler E, Chandra D, Mulpuri K, et al. NSAID exposure and risk of nonunion: a meta-analysis of case-control and cohort studies. Calcif Tissue Int. 2010;87(3):193-202.

14. Ding L, He Z, Xiao H, Chai L, Xue F. Factors affecting the incidence of aseptic nonunion after surgical fixation of humeral diaphyseal fracture. J Orthop Sci. 2014;19(6):973-7.

15. Bhandari M, Tornetta P, 3rd, Sprague S, Najibi S, Petrisor B, Griffith L, et al. Predictors of reoperation following operative management of fractures of the tibial shaft. J Orthop Trauma. 2003;17(5):35361. 
16. Yang JJ, Lin LC, Chao KH, Chuang SY, Wu CC, Yeh TT, et al. Risk factors for nonunion in patients with intracapsular femoral neck fractures treated with three cannulated screws placed in either a triangle or an inverted triangle configuration. J Bone Joint Surg Am. 2013;95(1):61-9.

17. Zura R, Braid-Forbes MJ, Jeray K, Mehta S, Einhorn TA, Watson JT, et al. Bone fracture nonunion rate decreases with increasing age: A prospective inception cohort study. Bone. 2017;95:26-32.

18. Zura R, Watson JT, Einhorn T, Mehta S, Della Rocca GJ, Xiong Z, et al. An inception cohort analysis to predict nonunion in tibia and 17 other fracture locations. Injury. 2017;48(6):1194-203.

19. Ali A, Douglas H, Stanley D. Revision surgery for nonunion after early failure of fixation of fractures of the distal humerus. J Bone Joint Surg Br. 2005;87(8):1107-10.

20. Mills LA, Aitken SA, Simpson A. The risk of non-union per fracture: current myths and revised figures from a population of over 4 million adults. Acta Orthop. 2017;88(4):434-9.

21. Meidinger G, Imhoff AB, Paul J, Kirchhoff C, Sauerschnig M, Hinterwimmer S. May smokers and overweight patients be treated with a medial open-wedge HTO? Risk factors for non-union. Knee Surg Sports Traumatol Arthrosc. 2011;19(3):333-9.

22. Ziran B, Cheung S, Smith W, Westerheide K. Comparative efficacy of 2 different demineralized bone matrix allografts in treating long-bone nonunions in heavy tobacco smokers. Am J Orthop (Belle Mead NJ). 2005;34(7):329-32.

23. Duckworth AD, Bennet SJ, Aderinto J, Keating JF. Fixation of intracapsular fractures of the femoral neck in young patients: risk factors for failure. J Bone Joint Surg Br. 2011;93(6):811-6.

24. Cappuccio FP, Meilahn E, Zmuda JM, Cauley JA. High blood pressure and bone-mineral loss in elderly white women: a prospective study. Study of Osteoporotic Fractures Research Group. Lancet. 1999;354(9183):971-5.

25. Hernandez RK, Do TP, Critchlow CW, Dent RE, Jick SS. Patient-related risk factors for fracture-healing complications in the United Kingdom General Practice Research Database. Acta Orthop. 2012;83(6):653-60.

26. Solomon DH, Hochberg MC, Mogun H, Schneeweiss S. The relation between bisphosphonate use and non-union of fractures of the humerus in older adults. Osteoporos Int. 2009;20(6):895-901.

27. van Wunnik BP, Weijers PH, van Helden SH, Brink PR, Poeze M. Osteoporosis is not a risk factor for the development of nonunion: A cohort nested case-control study. Injury. 2011;42(12):1491-4.

28. Calori GM, Albisetti W, Agus A, lori S, Tagliabue L. Risk factors contributing to fracture non-unions. Injury. 2007;38 Suppl 2:S11-8.

29. Zura R, Xiong Z, Einhorn T, Watson JT, Ostrum RF, Prayson MJ, et al. Epidemiology of Fracture Nonunion in 18 Human Bones. JAMA Surg. 2016;151(11):e162775.

30. Metsemakers WJ, Handojo K, Reynders P, Sermon A, Vanderschot P, Nijs S. Individual risk factors for deep infection and compromised fracture healing after intramedullary nailing of tibial shaft fractures: a single centre experience of 480 patients. Injury. 2015;46(4):740-5. 
31. Simon AM, O'Connor JP. Dose and time-dependent effects of cyclooxygenase-2 inhibition on fracture-healing. J Bone Joint Surg Am. 2007;89(3):500-11.

32. Jeffcoach DR, Sams VG, Lawson CM, Enderson BL, Smith ST, Kline H, et al. Nonsteroidal antiinflammatory drugs' impact on nonunion and infection rates in long-bone fractures. J Trauma Acute Care Surg. 2014;76(3):779-83.

33. Giannoudis PV, MacDonald DA, Matthews SJ, Smith RM, Furlong AJ, De Boer P. Nonunion of the femoral diaphysis. The influence of reaming and non-steroidal anti-inflammatory drugs. J Bone Joint Surg Br. 2000;82(5):655-8.

34. Goodship AE, Cunningham JL, Kenwright J. Strain rate and timing of stimulation in mechanical modulation of fracture healing. Clin Orthop Relat Res. 1998(355 Suppl):S105-15.

35. Bailón-Plaza A, van der Meulen MC. Beneficial effects of moderate, early loading and adverse effects of delayed or excessive loading on bone healing. J Biomech. 2003;36(8):1069-77.

36. Westgeest J, Weber D, Dulai SK, Bergman JW, Buckley R, Beaupre LA. Factors Associated With Development of Nonunion or Delayed Healing After an Open Long Bone Fracture: A Prospective Cohort Study of 736 Subjects. J Orthop Trauma. 2016;30(3):149-55.

37. Houben IB, Raaben M, Van Basten Batenburg M, Blokhuis TJ. Delay in weight bearing in surgically treated tibial shaft fractures is associated with impaired healing: a cohort analysis of 166 tibial fractures. Eur J Orthop Surg Traumatol. 2018;28(7):1429-36.

38. Schemitsch EH, Bhandari M, Guyatt G, Sanders DW, Swiontkowski M, Tornetta P, et al. Prognostic factors for predicting outcomes after intramedullary nailing of the tibia. J Bone Joint Surg Am. 2012;94(19):1786-93.

39. Audigé L, Griffin D, Bhandari M, Kellam J, Rüedi TP. Path analysis of factors for delayed healing and nonunion in 416 operatively treated tibial shaft fractures. Clin Orthop Relat Res. 2005;438:221-32.

40. Salem KH. Critical analysis of tibial fracture healing following unreamed nailing. Int Orthop. 2012;36(7):1471-7. 